\title{
ON THE RANGE OF THE PARAMETERS FOR THE GRAND FURUTA INEQUALITY TO BE VALID II
}

\section{KEIICHI WATANABE}

Abstract. We will investigate the range of the parameters which make the grand Furuta inequality valid.

Mathematics subject classification (2010): Primary 47A63; Secondary 15A45.

Keywords and phrases: Löwner-Heinz inequality, Furuta inequality, matrix inequality.

\section{REFERENCES}

[1] T. Ando And F. HiaI, Log majorization and complementary Golden-Thompson type inequalities, Linear Algebra Appl. 197/198 (1994), 113-131

[2] T. FURUTA, $A \geqslant B \geqslant 0$ assures $\left(B^{r} A^{p} B^{r}\right)^{1 / q} \geqslant B^{(p+2 r) / q}$ for $r \geqslant 0, p \geqslant 0, q \geqslant 1$ with $(1+2 r) q \geqslant$ $p+2 r$, Proc. Amer. Math. Soc. 101 (1987), no. 1, 85-88.

[3] T. FurutA, Extension of the Furuta inequality and Ando-Hiai log-majorization, Linear Algebra Appl. 219 (1995), 139-155.

[4] E. HEINZ, Beiträge zur Störungstheorie der Spektralzerlegung, Math. Ann. 123 (1951), 415-438.

[5] T. KoIZUmi AND K. WATANABE, Another consequence of Tanahashi's argument on best possibility of the grand Furuta inequality, Cent. Eur. J. Math. 11 (2) (2013), 368-375, DOI: 10.2478/s11533012-0061-3.

[6] K. LöWnER, Über monotone Matrixfunktionen, Math. Z. 38 (1934), 177-216.

[7] K. Tanahashi, Best possibility of the Furuta inequality, Proc. Amer. Math. Soc. 124 (1996), 141 146.

[8] K. Tanahashi, The best possibility of the grand Furuta inequality, Proc. Amer. Math. Soc. 128 (2000), 511-519.

[9] K. WATANABE, A certain functional inequality derived from an operator inequality, to appear in J. Math. Inequal.

[10] K. WATANABE, On the range of the parameters for the grand Furuta inequality to be valid, preprint. 